Article (refereed) - postprint

Hou, Xikang; Zhan, Xiaoying; Zhou, Feng; Yan, Xiaoyuan; Gu, Baojing; Reis, Stefan; Wu, Yali; Liu, Hongbin; Piao, Shilong; Tang, Yanhong. 2018.

Detection and attribution of nitrogen runoff trend in China's croplands. Environmental Pollution, 234. 270-278.

https://doi.org/10.1016/i.envpol.2017.11.052

(C) 2017 Elsevier Ltd

This manuscript version is made available under the CC-BY-NC-ND 4.0 license http://creativecommons.org/licenses/by-nc-nd/4.0/

(c) EY-NC-ND

This version available http://nora.nerc.ac.uk/id/eprint/519610/

NERC has developed NORA to enable users to access research outputs wholly or partially funded by NERC. Copyright and other rights for material on this site are retained by the rights owners. Users should read the terms and conditions of use of this material at http://nora.nerc.ac.uk/policies.html\#access

NOTICE: this is the author's version of a work that was accepted for publication in Environmental Pollution. Changes resulting from the publishing process, such as peer review, editing, corrections, structural formatting, and other quality control mechanisms may not be reflected in this document. Changes may have been made to this work since it was submitted for publication. A definitive version was subsequently published in Environmental Pollution, 234. 270-278. https://doi.org/10.1016/j.envpol.2017.11.052 www.elsevier.com/ 
The NERC and CEH trademarks and logos ('the Trademarks') are registered trademarks of NERC in the UK and other countries, and may not be used without the prior written consent of the Trademark owner. 
$21{ }^{+}$X.K.H and X.Y.Z contributed equally to this work. (1) Beijing, 100871, P.R. China China Estate, Penicuik EH26 0QB, United Kingdom Agricultural Sciences, Beijing 100081, P.R. China Kingdom

\section{Detection and attribution of nitrogen runoff trend in China's croplands}

Xikang Hou ${ }^{1,+}$, Xiaoying Zhan ${ }^{1,+}$, Feng Zhou ${ }^{1, *}$, Xiaoyuan Yan ${ }^{2}$, Baojing $\mathrm{Gu}^{3}$, Stefan Reis ${ }^{4,6}$, Yali Wu ${ }^{1}$, Hongbin Liu ${ }^{5}$, Shilong Piao ${ }^{1}$, Yanhong Tang ${ }^{1}$

1. Sino-France Institute of Earth Systems Science, Laboratory for Earth Surface Processes, College of Urban and Environmental Sciences, Peking University,

2. State Key Laboratory of Soil and Sustainable Agriculture, Institute of Soil Science, Chinese Academy of Sciences, Nanjing, 210008, P.R. China

3. Department of Land Management, Zhejiang University, Hangzhou 310058, P.R.

4. Natural Environment Research Council, Centre for Ecology \& Hydrology, Bush

5. Institute of Agricultural Resources and Regional Planning, Chinese Academy of

6. University of Exeter Medical School, Knowledge Spa, Truro, TR1 3HD, United 


\section{Acronyms and Abbreviations}

$\begin{array}{llll}R_{T N} & \text { Cropland N runoff } & R R & \mathrm{R}_{\mathrm{TN}} \text { per unit N fertilizer additions } \\ R^{0} & \text { Background N runoff } & p H & \text { Soil pH value } \\ \text { SOM } & \text { Soil organic matter } & \text { Clay } & \text { Soil clay content } \\ T N & \text { Soil total nitrogen } & \text { Temp } & \text { Mean air temperature } \\ N_{\text {rate }} & \text { Nitrogen (N) fertilizer application } & \text { W } & \text { Sum of precipitation and irrigation } \\ & & & \\ & \text { rate per unit sowing area } & & \text { within observation period } \\ x_{k} & \text { Environmental variables } & C E & \text { Correction coefficient }\end{array}$




\section{Abstract}

Reliable detection and attribution of changes in nitrogen $(\mathrm{N})$ runoff from croplands are essential for designing efficient, sustainable $\mathrm{N}$ management strategies for future. Despite the recognition that excess $\mathrm{N}$ runoff poses a risk of aquatic eutrophication, large-scale, spatially detailed $\mathrm{N}$ runoff trends and their drivers remain poorly understood in China. Based on data comprising 535 site-years from 100 sites across China's croplands, we developed a data-driven upscaling model and a new simplified attribution approach to detect and attribute N runoff trends during the period of 19902012. Our results show that $\mathrm{N}$ runoff has increased by $46 \%$ for rice paddy fields and 31\% for upland areas since 1990. However, we acknowledge that the upscaling model is subject to large uncertainties (20\% and $40 \%$ as coefficient of variation of $\mathrm{N}$ runoff, respectively). At national scale, increased fertilizer application was identified as the most likely driver of the $\mathrm{N}$ runoff trend, while decreased irrigation levels offset to some extent the impact of fertilization increases. In southern China, the increasing trend of upland $\mathrm{N}$ runoff can be attributed to the growth in $\mathrm{N}$ runoff rates. Our results suggested that increased SOM led to the N runoff rate growth for uplands, but led to a decline for rice paddy fields. In combination, these results imply that improving management approaches for both $\mathrm{N}$ fertilizer use and irrigation is urgently required for mitigating agricultural $\mathrm{N}$ runoff in China.

Keywords: Nitrogen runoff; temporal trend; spatial pattern; attribution analysis; 


\section{Capsule}

47 Cropland $\mathrm{N}$ runoff in China increased by $30 \%$ over the past two decades mainly due to 48 increased fertilization and decreased irrigation.

49

\section{$50 \quad$ Highlights}

51 - A data-driven upscaling model can effectively and reliably detect $\mathrm{N}$ runoff trends

- $\quad \mathrm{N}$ runoff has increased by $46 \%$ for rice paddy fields and $31 \%$ for uplands since

53 1990

54

- $\quad$ SOM change results in inverse trend of $\mathrm{N}$ runoff rates between upland and rice

55 fields

56 


\section{Introduction}

58 Meeting food security targets while simultaneously reducing reactive nitrogen losses

59 has drawn attention from both scientists and the public (Chen et al., 2014; Mueller et

60 al., 2012; Tilman et al., 2011; Zhang et al., 2015). Large amounts of anthropogenic

61 nitrogen $(\mathrm{N})$ inputs have resulted in excess $\mathrm{N}$ being lost in runoff from croplands to

62 water bodies and the atmosphere worldwide (Cui et al., 2014; Leip et al., 2011;

63 Seitzinger et al., 2010). As one of the consequences, increased occurrences of aquatic

64 eutrophication and ecosystem degradation were observed, particularly in China and

65 South Asia (Paerl et al., 2014). Reliable detection and attribution of cropland N runoff

66 are crucial for policy makers and farmers to develop site-specific $\mathrm{N}$ management

67 strategies (Cherry et al., 2008). Although cropland N runoff is substantial in China (e.g.,

$682.1 \pm 0.2$ or $0.8 \mathrm{Tg} \mathrm{N} \mathrm{yr}^{-1}$ estimated by Gu et al., (2015) and Wang et al., (2014),

69 respectively), large-scale, spatially detailed $\mathrm{N}$ runoff trends and its attribution remain

70 poorly understood.

71

72 Cropland $\mathrm{N}$ runoff, defined as a generation process of $\mathrm{N}$ loss via surface runoff, depends

73 on environmental conditions and agricultural management practices (Zhang et al.,

74 2016). This complexity makes large-scale $N$ runoff difficult to estimate using empirical

75 models. Plot-scale $\mathrm{N}$ runoff flux data from croplands are also difficult to scale up into

76 spatially detailed maps because of spatio-temporally varying results (Shen et al., 2012).

77 Currently, an export coefficient approach has been widely used to estimate cropland $\mathrm{N}$ 
runoff (Hao, 2006; Liu et al., 2010; Velthof et al., 2009; Wang et al., 2014). For example, the first National Pollution Census Program of China (NPCP) provided a collection of $\mathrm{N}$ runoff flux coefficients for different geographical regions in China, determined by fitting cross-sectional site data to an export-coefficient model (Wang et al., 2014). Nevertheless, substantial evidence gathered from field observations indicates that linear and homogeneous models are rarely capable of capturing the spatial variability of $\mathrm{N}$ runoff at regional scale (Schaefer and Alber, 2007; Sobota et al., 2009; Hou et al., 2016). This highlights the difficulty of accurately predicting its future evolution as well as quantifying the impacts on aquatic ecosystems.

While it is still challenging to attribute contributions of each individual driving factor (e.g., climate condition, agricultural management practices) to the cropland $\mathrm{N}$ runoff trend assessment, statistical correlation or regression analyses have been widely applied (Korsaeth and Eltun, 2000; Stalnacke et al., 2015) over past decades. However, this approach has two potential limitations. Firstly, statistical analyses of historical RTN generally characterizes the related major drivers, thus includes the signals not only from the temporal trends, but also from inter-annual or decadal variability. Secondly, the use of statistical analysis generally assumes that the effects of drivers on $\mathrm{N}$ runoff are linear and independent of each other (Piao et al., 2015). However, a growing number of studies based on both data from field experiments and theoretical analyses indicated non-linear responses of $\mathrm{N}$ runoff to changes in driving factors as a consequence of 

analysis could be overcome through the application of process-based models (Hao,

101 2006; Abbaspour et al., 2015, Liu et al. 2016), core limitations of such simulation 102 models are the large uncertainties arising from model structure and parameter choice 103 (Schulz et al., 1999). One way to separate the contribution of natural and anthropogenic 104 controls is to use the Kaya Identity concept developed in economics (Raupach et al., 105 2007), which is adopted when studying climate change and hydrological science 106 (Streimikiene and Balezentis, 2016; Wang et al., 2015b).

108 To quantify and attribute cropland $\mathrm{N}$ runoff trends during past decades, we analyzed the 109 data in this study is based on a upscaling model following a new simple attribution 110 approach. Synthesized field measurements were used for model calibration and cross111 validation based on the Bayesian Recursive Regression Tree algorithm version 2.0 112 (BRRT v2, Zhou et al., 2015), utilizing high-resolution gridded datasets including 113 climate conditions, soil attributes, and agricultural management practices. First, we 114 assessed inter-annual dynamics of cropland $\mathrm{N}$ runoff derived from the data-driven 115 upscaling model to detect trends for the period from 1990 to 2012. Second, we 116 compared the proportional change rate of each driver to upscaling results of $\mathrm{R}_{\mathrm{TN}}$, which 117 allowed us to diagnose the contributions of different drivers. Finally, we discussed how 118 each driver modulates the temporal trend of $\mathrm{R}_{\mathrm{TN}}$ and the implications for site-specific 119 N management. 


\section{2. Data and methodology}

122

123

124

\subsection{Dataset}

Based on the National Pollution Census Program of China (NPCP) and datasets published by the scientific community, in situ measurements of $\mathrm{N}$ runoff and associated variables in each plot were collated from 100 experimental sites for both rice paddy and upland fields (i.e., as a flooded parcel of arable land used for growing rice and non-rice crops, respectively). Water samples were collected in the drainage outlet for each rainfall event in most of the measurements, where the runoff volume was consecutively measured within the observation period. $\mathrm{N}$ concentrations in water samples were analyzed using ultraviolet spectrophotometric methods, following the Standard Methods for the Examination of Water and Wastewater approach for China (SEPA, 2002). Precipitation within the observation period and soil properties (0-20 cm depth) at the beginning of the experiment were synchronously monitored. Missing values of soil properties or climatic factors at a few sites were supplemented with data from the China Soil Scientific Database (http://vdb3.soil.csdb.cn/) based on the corresponding soil type of the county or from the 0.1-degree China Meteorological Forcing Dataset (CMFD) v0106 (http://data.cma.cn/) depending on its geographic coordinates. Information on agricultural management practices including $\mathrm{N}$ fertilizer application rate, irrigation amount, fertilizer types, and crop types were recorded, including the timing of the application. The dataset comprised 535 site-years data (293 for upland 
141 and 242 for rice paddy fields) (Fig. 1a and Supplementary Data S1), and can be 142 considered representative of most major cropping areas except northwestern China (Fig. $1431)$.

144

145 conditions and agricultural management (Eq. 1). Specifically, $\mathrm{N}$ fertilizer application

Figure 1. Location of experimental sites on cropland $\mathbf{N}$ runoff in China. Sixty-two experimental sites for upland are illustrated as black solid circles, whereas thirty-eight sites for paddy field are indicated as red solid circles. The ranges of each individual variable is illustrated as a light red bar for observational datasets and a dark red bar for croplands for the whole of China in panel b. The variables are $N_{\text {rate }}\left(\mathrm{kg} \mathrm{N} \mathrm{ha}^{-1}\right)$, clay content (Clay, \%), water input (W, mm), soil pH, soil organic matter (SOM, $\mathrm{g} \mathrm{kg}^{-1}$ ), soil TN ( $\left.\mathrm{g} \mathrm{kg}^{-1}\right)$ and air temperature (Temp, $\left.{ }^{\circ} \mathrm{C}\right)$.

\subsection{Data-driven upscaling model}

We developed an upscaling model which accounts for the effects of environmental rate $\left(N_{\text {rate }}\right)$ and environmental conditions $\left(x_{k}\right)$ are directly included as independent a

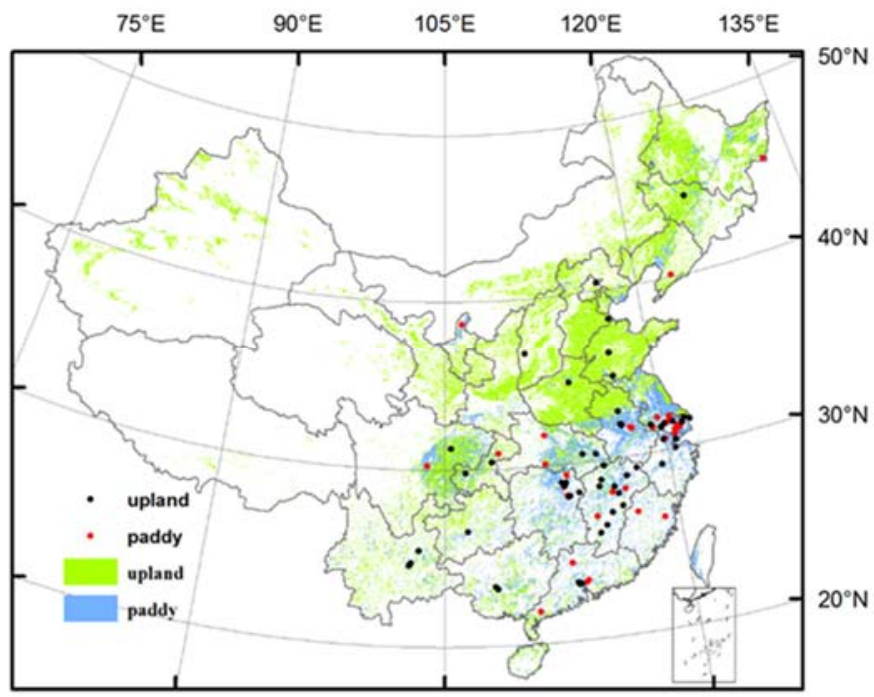

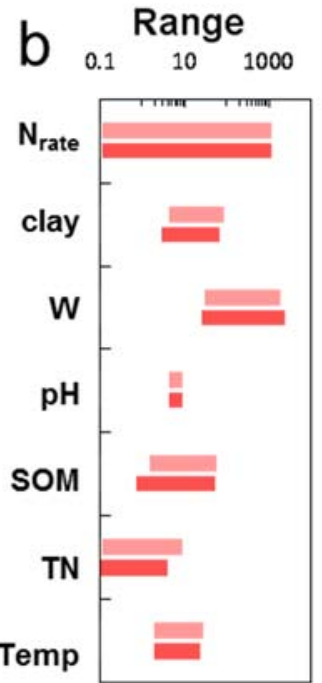


176 The Bayesian Recursive Regression Tree version 2 (Zhou et al., 2015), was 177 subsequently used with observational data to determine optimal $L, f\left(x_{k}\right), g\left(x_{k}\right)$, and $h\left(x_{k}\right)$.

and $i$ and $j$ represent the index of fertilizer types and crop types, respectively; $l$ and $L$ are the index and number of piecewise functions. $x_{k}$ is climatic condition or soil attribute. Observations (Fig. S1) of air temperature, water input and soil clay content can be used as proxies to reflect the variations of soil temperature and water content within the observation period, respectively. $R R^{*}$ and $R^{0, *}$ are the reference values when urea is applied and where wheat or rice are cultivated on experimental sites. Both are then adjusted to reflect different fertilizer and crop types to develop a specific $R R$ and $R^{0}$ for a given scenario. The details of correction coefficients (CEs) can be found in Table S1. It should be noted that fertilizer types considered include urea, compound fertilizers, manure and/or crop residues, and ammonium bicarbonate. In addition, crop types distinguish between rice, wheat, maize, soybean, cotton, and other corps. 
179 and Text S2 in the Suppl. Mat.. The resulting calibrated model was applied to simulate 180 spatial patterns of $\mathrm{N}$ runoff over Chinese croplands from 1990 to 2012 at a spatial 181 resolution of $1 \mathrm{~km}$. The details on input data used in this model, including $N_{\text {rate }}$ by 182 fertilizer and crop types, water input, clay content, air temperature, soil pH, soil organic 183 matter (SOM), and soil N, are described in Table S2 and Fig. S2. Due to the lack of 184 detailed information on the spatio-temporal changes in fertilization methods, timing, 185 and cultivation practices in China, this information was not included in the data-driven 186 upscaling model simulation presented here.

\subsection{Structural decomposition analysis}

189 We further applied a simplified attribution approach, 'Runoff Identity' (analogous to

190 the Kaya Identity in economics), to assess the contribution of water input changes ( $W$,

191 the sum of precipitation and irrigation amounts), the fertilizer-to-water ratio (the ratio 192 of fertilizer used to water input) and $\mathrm{N}$ runoff rate (i.e., the ratio of annual $\mathrm{N}$ runoff flux 193 to fertilizer addition) to the relative rate of change of RTN in China. The Runoff Identity 194 combines the variables of regional averaged water inputs and fertilizer addition in a 195 causal relationship to cropland $\mathrm{N}$ runoff $\left(\mathrm{R}_{\mathrm{TN}}\right)$. $\mathrm{R}_{\mathrm{TN}}$ is therefore regarded as the 196 integration of the three variables:

$$
R_{T N}=W\left(\frac{N_{\text {rate }}}{W}\right)\left(\frac{R_{T N}}{N_{\text {rate }}}\right)=w \cdot f \cdot e
$$

We then defined the proportional change rate of a quantity $X(t)$ as $r(X)=X^{-1} \mathrm{~d} X / \mathrm{d} t$ (with units [time] $\left.]^{-1}\right)$. Because $\left(\left(\mathrm{d} R_{T N} / \mathrm{d} t\right) / R_{T N}\right)=\left(\left(\mathrm{d} R_{T N} / \mathrm{d} t\right) /(w f e)\right)=((\mathrm{d} w / \mathrm{d} t) / w)+((\mathrm{d} f / \mathrm{d} t) / f)+$ 
$200((\mathrm{de} / \mathrm{d} t) / e)$, the Runoff Identity for proportional change rate can be rewritten as

$$
r\left(R_{T N}\right)=r(w)+r(f)+r(e)
$$

202 Using time-series data of $w, f$ and $e$, we applied this approach to quantify the role of 203 each driver in relation to changes of the RTN trend. The theoretical proportional change 204 rate, which was a sum of factors $w, f$ and $e$, closely approximates the rate of $\mathrm{R}_{\mathrm{TN}}$ that 205 actually occurred. We calculate their rates of change over the whole period from 1990 to 2012 using a linear regression method, and normalized them by corresponding mean values, respectively. The relative contribution of each factor is the ratio of its proportional change rate to the proportional change rate of $\mathrm{R}_{\mathrm{TN}}$ during the same period.

\section{Results}

\subsection{Model performance}

The data-driven upscaling model (Table S3) was evaluated by reviewing the coefficient

213 of determination $\left(\mathrm{R}^{2}\right)$ and coefficient of variation (CV, calculated as the ratio of root-

214 mean-squared error to mean value), which were 0.85 and $39 \%$ for rice paddy fields 215 (n=242, Fig. 2a), and 0.85 and 50\% for upland grain crops (n=293, Fig. 2b), respectively.

216 The evaluation results suggest that most of the variance of $\mathrm{R}_{\mathrm{TN}}$ could be explained by 217 the model with acceptable bias. Model performance for $\mathrm{R}_{\mathrm{TN}}$ per unit $\mathrm{N}$ fertilizer 218 additions (RR) $\left(R^{2}=0.71\right.$ and $n=75$ for rice paddy fields, Fig. 2c; $R^{2}=0.40$ and $n=$ 219146 for uplands, Fig. 2d) further indicate that our model is able to capture the sensitivity 220 of R $\mathrm{R}_{\mathrm{TN}}$ to $\mathrm{N}$ inputs. Regionally, there are no evident differences in model performance 
221 of $\mathrm{R}_{\mathrm{TN}}$ across the 7 regions (Fig. 2), but $R R$ simulated by our model shows differences

222 compared to observations in East China in particular. Additionally, a few simulated $R R$

223 were different from the observations (Fig. 2), mainly due to the lack of spatially detailed

224 data on specific fertilization methods, cultivation practices, or rainfall intensity in our

225 models (Liu et al., 2016; Miyazato et al., 2010; Wang et al., 2015a; Xu et al., 2013).
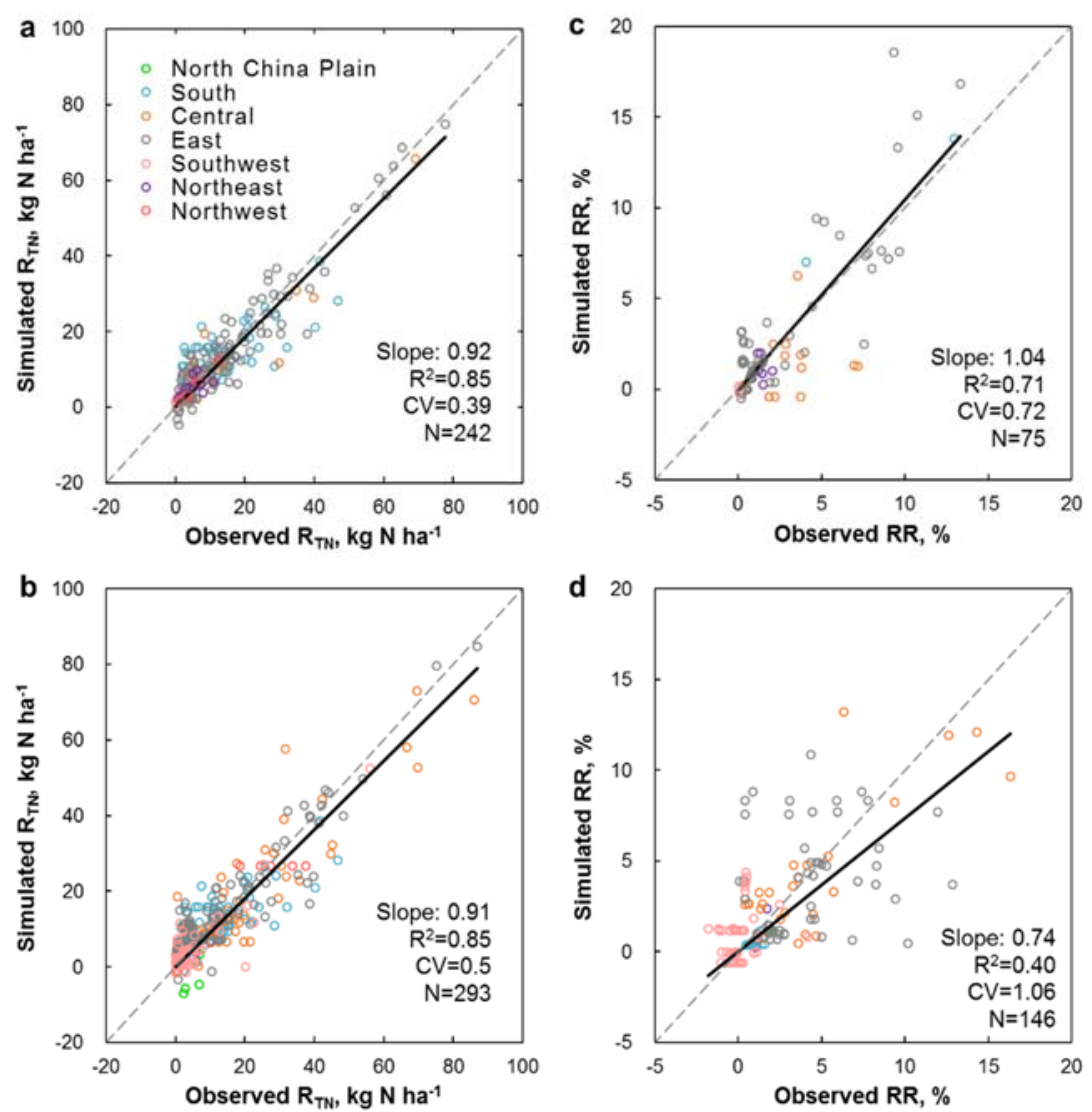

Figure 2. Calibration of $R_{T N}$, $R R$ for paddy fields (panels a and c) and upland

(panels $\mathbf{b}$ and d). The slope, $\mathrm{R}^{2}$, and coefficient of variation (CV) are indicated in the insets at the bottom right of each panel. Dots are colored in Fig. 2 to indicate model performances in different regions in China. 


\section{2 $\mathrm{N}$ runoff trends and their spatial patterns}

233 Figures 3a and 3b show the annual N runoff or runoff rate from China's rice paddy and 234 upland soils from 1990 to 2012, respectively. In 1990, R $\mathrm{R}_{\mathrm{TN}}$ was $1.69 \pm 0.80 \mathrm{Tg} \mathrm{N} \mathrm{\textrm {yr } ^ { - 1 }}$ 235 in China ( $\sigma$ is the standard deviation of $\mathrm{N}$ runoff due to the uncertainties of input data 236 and model parameters), splitting into $0.46 \pm 0.08 \mathrm{Tg} \mathrm{N} \mathrm{yr}^{-1}$ for paddy field and $1.23 \pm$ $2370.51 \mathrm{Tg} \mathrm{N} \mathrm{yr}^{-1}$ for upland (Fig. 3). More details of uncertainty estimation approach 238 using Monte Carlo ensemble simulations can be found in Text S3. RTN had increased 239 by 2012 by $46 \pm 11 \%$ for rice paddy fields and $31 \pm 14 \%$ for uplands ( $\sigma$ is the standard deviation of $\mathrm{N}$ runoff changes occurring over a 23-year period; Fig. 3a and 3b).
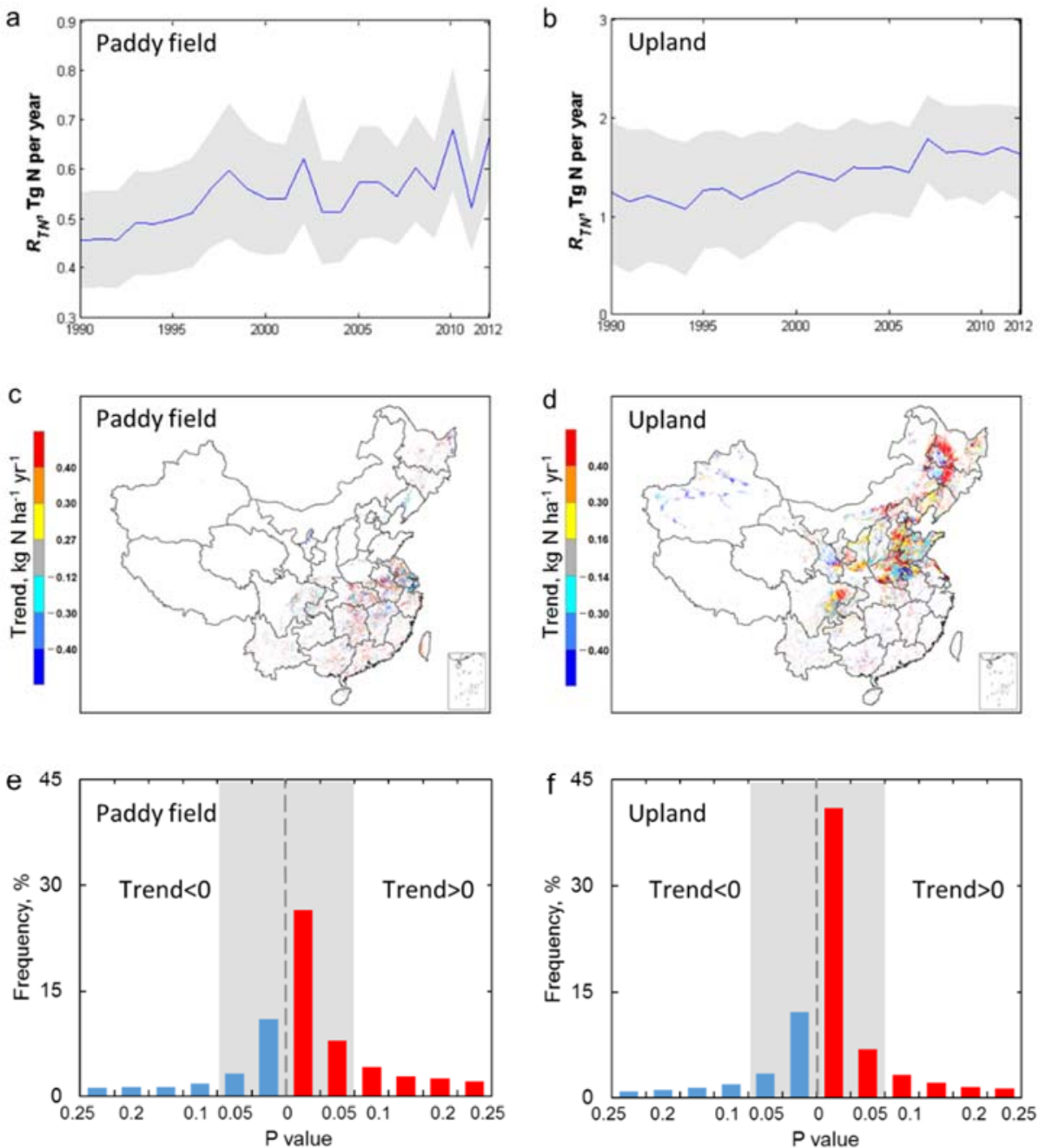
243 (b) upland; (c) spatial pattern of $\mathrm{N}$ runoff trend for paddy field; (d) the same as for c but

244 for upland; (e) frequency distribution of the significance level (P-value) of N runoff

245 trend for paddy field; (f) the same as for e but for upland. The P -value of N runoff

246 trends for each pixel is estimated based on T test. The gray shaded areas in panels (a)

247 and (b) reflect standard deviations based on uncertainty assessments (see Text S2).

249 Spatial patterns of the N runoff trends across China for the period from 1990 to 2012 250 were for the land area of China by applying the upscaling model are displayed in Figs.

251 3c and 3d. Both simulation results for rice paddy fields and uplands consistently showed that $\mathrm{N}$ runoff trend increased in most regions of China $(P<0.01$ according to the Mann-

253 Kendall test), while the magnitude of the $\mathrm{R}_{\mathrm{TN}}$ trend varied for different croplands in 254 China. For rice paddy soils, regions with the largest $\mathrm{R}_{\mathrm{TN}}$ trend are generally found in 255 southern China and parts of northeastern China (i.e., Amour-Ussuri-Songhua River 256 Plain, defined in Fig. S3), where the trend of $\mathrm{R}_{\mathrm{TN}}$ is generally larger than $0.4 \mathrm{~kg} \mathrm{~N} \mathrm{ha}^{-1}$ $257 \mathrm{yr}^{-2}$. However, regions that experienced a decreasing trend (14\% of croplands) were 258 located in the lower reaches of the Yangtze River Basin, Ningxia Plain, and part of the 259 Sichuan Basin (Fig. S3), where the trend of $\mathrm{R}_{\mathrm{TN}}$ is $-0.12 \mathrm{~kg} \mathrm{~N} \mathrm{ha}^{-1} \mathrm{yr}^{-2}$. For uplands, 260 the highest values of the $\mathrm{R}_{\mathrm{TN}}$ trend $\left(>0.4 \mathrm{~kg} \mathrm{~N} \mathrm{ha}^{-1} \mathrm{yr}^{-2}\right)$ are found in northeast China, 261 the Guanzhong Plain, and parts of the North China Plain and Sichuan Basin. In contrast, 262 regions with a decreasing $\mathrm{R}_{\mathrm{TN}}$ trend (16\% of croplands) include the Shandong Peninsula, 
upper reaches of the Huaihe River Basin, and northwest China $\left(-0.14 \mathrm{~kg} \mathrm{~N} \mathrm{ha}^{-1} \mathrm{yr}^{-2}\right)$.

264 The $\mathrm{R}_{\mathrm{TN}}$ trend is statistically insignificant $(\mathrm{P}>0.05)$ in less than $40 \%$ of croplands, 265 mainly in the Yangtze River Basin, Shandong Peninsula and Shanxi province (Fig. 3e 266 and 3f).

\subsection{Attribution of $\mathrm{N}$ runoff trends at national scale}

For rice paddy fields (Fig. 4a), the relative rate of change of $\mathrm{R}_{\mathrm{TN}}$ at national scale was to-water ratio, but partly offset by the decline of water input (28\%). For upland, the trend of $\mathrm{R}_{\mathrm{TN}}$ also showed an increase (1.9\% $\mathrm{yr}^{-1}$; Fig. 4b) during the period 1990-2012,

273 with the largest attributable contribution of fertilizer-to-water ratio and a positive 274 proportional change rate of $2.4 \% \mathrm{yr}^{-1}$ which was partially offset by the decreased water 275 input $\left(-0.5 \% \mathrm{yr}^{-1}\right)$. Fig. 4 also illustrates the trend of each identity for rice paddy fields 276 and uplands during different periods. The relative $\mathrm{R}_{\mathrm{TN}}$ change rate for rice paddy field 277 was $2.4 \% \mathrm{yr}^{-1}$ prior to the year 2000 , but gradually reduced to $1.4 \% \mathrm{yr}^{-1}$ during the 278 period of $1990-2005$ and then less than $1.2 \% \mathrm{yr}^{-1}$ during 1990-2012, primarily due to 279 the decreased growth rate of fertilizer-to-water ratio (3.0 to $1.5 \% \mathrm{yr}^{-1}$ ). However, the 280 trend of $\mathrm{R}_{\mathrm{TN}}$ for uplands increased from $0.15 \% \mathrm{yr}^{-1}$ before 2000 to $0.19 \% \mathrm{yr}^{-1} \mathrm{during}$ 281 the whole period. This could primarily be explained by the fact that the decrease of 282 growing fertilizer-to-water ratio (from 2.9 to $2.4 \% \mathrm{yr}^{-1}$ ) was totally offset by the change 283 in the $\mathrm{N}$ runoff rate (from -0.9 to $0.01 \% \mathrm{yr}^{-1}$ ). 


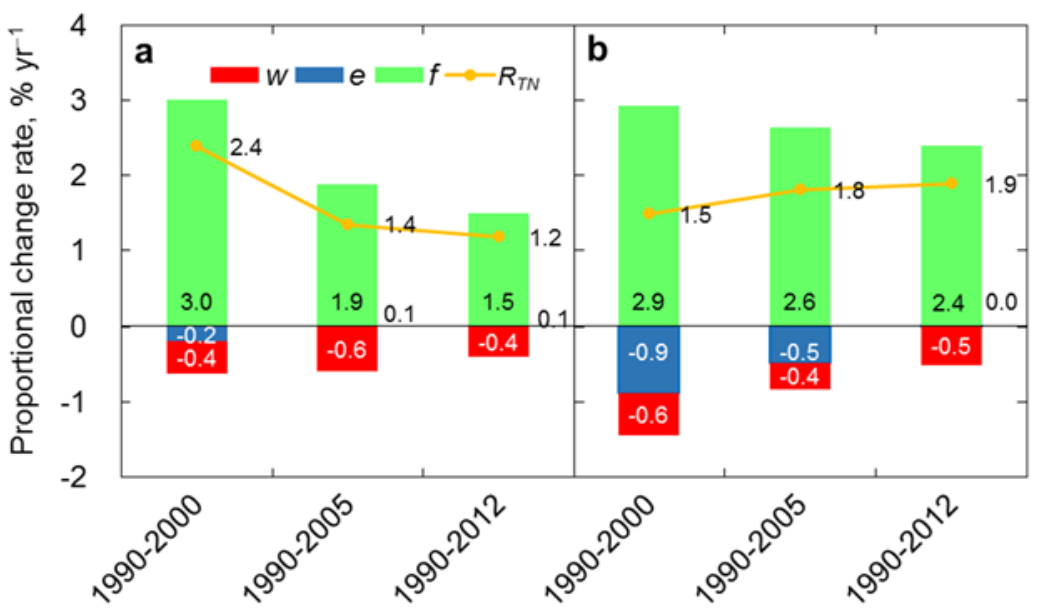

286 Figure 4. Proportional change rate of cropland $\mathbf{N}$ runoff and its drivers. (a) Paddy

287 field; (b) upland. Contributions of the N runoff identity factors during the years 1990288 2000, 1990-2005 and 1990-2012, including the water input of precipitation and 289 irrigation $(w), \mathrm{N}$ runoff rate $(e)$ and fertilizer-to-water ratio $(f)$.

\subsection{Spatial patterns of $\mathbf{N}$ runoff trend attributed to different drivers}

As demonstrated in Fig. 5, the contributions from three main driving factors to the trend in N runoff in eastern coastal regions, and Weihe River Basin (inset plot of Fig. 5a). 
substantial negative effect on the $\mathrm{R}_{\mathrm{TN}}$ trend in the other regions and the average trend

302 of RTN attributed to $\mathrm{N}$ runoff rate is $-1.12 \pm 1.07 \% \mathrm{yr}^{-1}$. In contrast to those two driving

303 factors, the relative contribution of water input to the $\mathrm{R}_{\mathrm{TN}}$ trend was minor, but remained

304 consistently negative for rice paddy fields across the whole country $\left(<-0.14 \% \mathrm{yr}^{-1}\right)$,

305 except for Taiwan $\left(1.06 \% \mathrm{yr}^{-1}\right)$, Shaanxi $\left(0.99 \% \mathrm{yr}^{-1}\right)$, and Ningxia provinces $(0.31 \%$ $\left.306 \mathrm{yr}^{-1}\right)$.

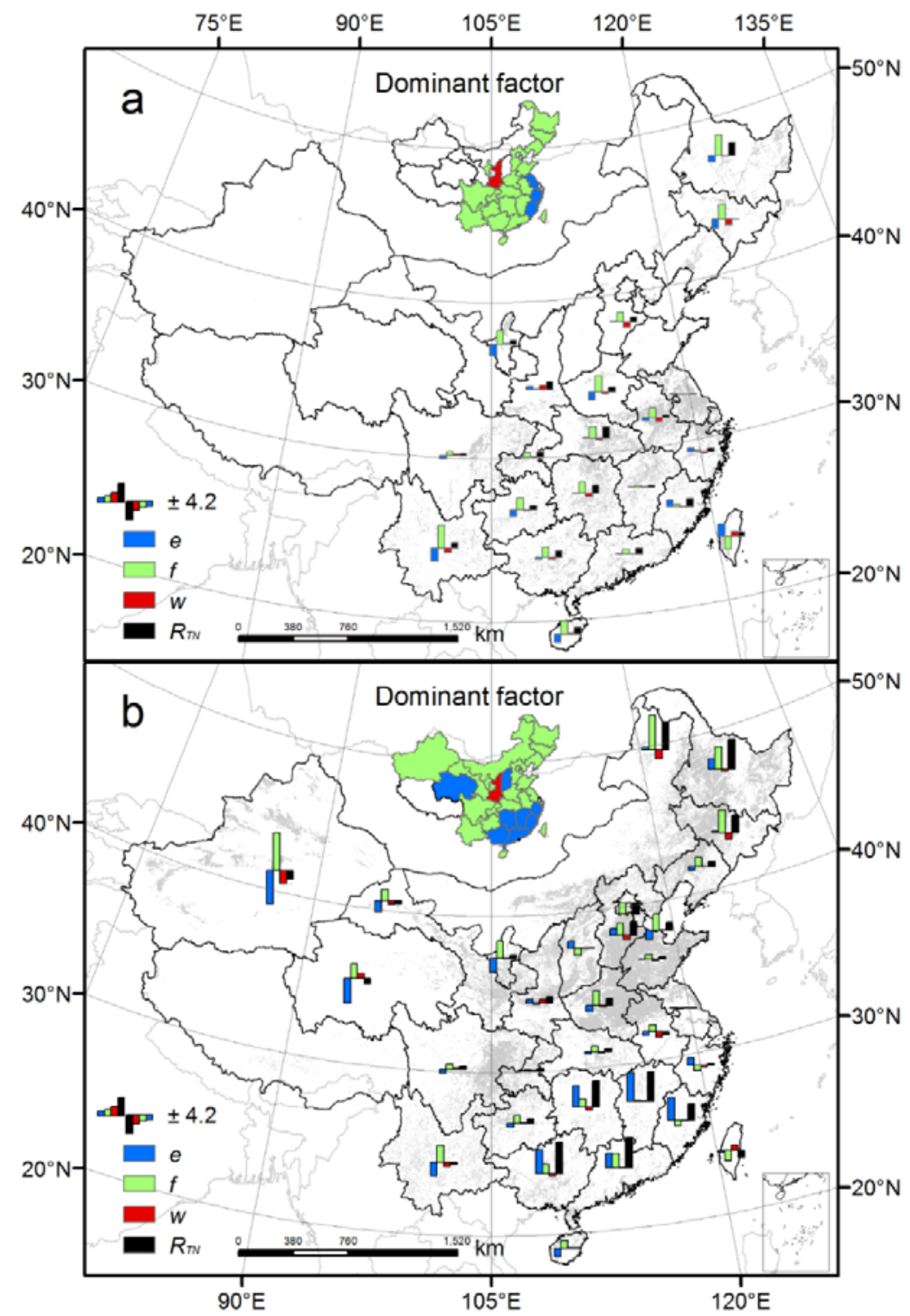

Figure 5. Trends in $\mathrm{N}$ runoff and its drivers during the period 1990-2012 at 
trend in each province are shown in the insets above the maps. The grey area shows the

311 spatial pattern of upland or paddy fields in China.

313 Fertilizer-to-water ratio contributed more to the $\mathrm{R}_{\mathrm{TN}}$ trend for uplands than for rice

314 paddy fields in the North China Plain and northeast Plain only. A positive effect of

315 fertilizer-to-water ratio on the $\mathrm{R}_{\mathrm{TN}}$ trend was largely offset by $\mathrm{N}$ runoff rate changes

316 across southern China and western China, where the trends of $\mathrm{R}_{\mathrm{TN}}$ attributed to $\mathrm{N}$ runoff

317 rate averaged at $4.36 \pm 1.67 \% \mathrm{yr}^{-1}$ and $-3.08 \pm 2.40 \% \mathrm{yr}^{-1}$, respectively. On the other

318 hand, the model estimates indicate that $\mathrm{N}$ runoff rate changes may result in $\mathrm{R}_{\mathrm{TN}}$

319 increases in southern China (except for Hainan and Taiwan), which were one-fold

320 higher than the negative effect found across most of northern China. Although there

321 was no apparent difference in spatial patterns as to water input trends between upland

322 and paddy field (Fig. 5), the relative contribution of water input to the RTN trend for

323 upland was less than that for paddy field. In contrast to other regions, water input in

324 Shaanxi, Taiwan and Hainan provinces has significantly increase $(P<0.01)$. The

325 increase in trend of $\mathrm{R}_{\mathrm{TN}}$ due to water input change in Shanxi was larger than due to $\mathrm{N}$

326 runoff rate and fertilizer-to-water ratio for both crop types. The observations in Taiwan

327 and Qinghai show that water input change played an important role in $\mathrm{R}_{\mathrm{TN}}$ increase,

328 albeit less than the other two driving factors, accounting for $1.2 \% \mathrm{yr}^{-1}$ and $1.1 \% \mathrm{yr}^{-1}$

329 of the trend of $\mathrm{R}_{\mathrm{TN}}$. In summary, the effects of agricultural management practices,

330 including fertilization and irrigation schemes, outweigh the influence of current climate 
change on model-derived $\mathrm{R}_{\mathrm{TN}}$ trend increase for both paddy field and upland.

\section{Discussion}

334 Our findings generally agree well with most prior works, with a few exceptions. For 335 example, Gu et al. (2015) applied an integrated $\mathrm{N}$ budget model to constrain the 336 magnitude and trend of $\mathrm{N}$ runoff from China's croplands, with an estimate of $\mathrm{R}_{\mathrm{TN}}$ of

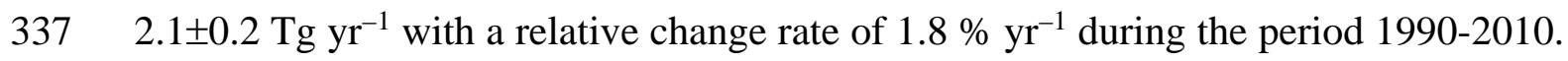
338 In our study, we explicitly incorporated the non-linear and spatially varied responses of 339 an RTN model at multiple $\mathrm{N}$ input levels and reached very similar estimates of total $\mathrm{N}$

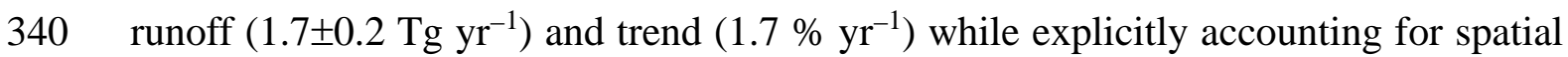
341 variability during the same period (Fig. S4). In addition, Ti and Yan (2013) indicated 342 that the fertilizer-induced N runoff in the Huanghe River Basin, the Yangtze River Basin, 343 and the Paerl River Basin was $1.06 \mathrm{Tg} \mathrm{yr}^{-1}$ in 2010 with a relative change rate of $1.4 \%$ $344 \mathrm{yr}^{-1}$ during the period from $1990-2010$, which is also comparable to our results $(0.72$ $345 \mathrm{Tg} \mathrm{yr}^{-1}$ in 2010 and $1.7 \% \mathrm{yr}^{-1}$ ). In general, using a new data-driven upscaling model, 346 our estimates derived from a large network of cropland $\mathrm{N}$ runoff observations, provide 347 novel insights into the spatially detailed N runoff trend for China’s croplands.

349 By developing a novel structured decomposition approach for a 'Runoff Identity' (see 350 section 2.3), we are able to accurately identify and quantify the contribution from each 351 individual driver including climatic and human-induced variables to $\mathrm{R}_{\mathrm{TN}}$ trend. Our 
352

371 large runoff pulses (Sorooshian et al., 2014). As we illustrated, the decline in water

results suggest that fertilization (or fertilizer-to-water ratio) is the dominant driver of $\mathrm{R}_{\mathrm{TN}}$ trends for both rice paddy fields and uplands across most of the country, which is consistent with experimental results at multiple N input levels (Liang et al., 2005; Shi et al., 2010; Yu, 2011). Indeed, over the last two decades, China experienced a growth rate in $\mathrm{N}$ fertilizer application of more than $4.0 \mathrm{~kg} \mathrm{~N} \mathrm{ha}^{-1} \mathrm{yr}^{-1}$ on average in response to a continuous increase in crop production (Fig. S5a). Previous studies suggest that this high rate of $\mathrm{N}$ additions to agricultural systems resulted in an increase in soil residual N (Yan et al., 2014). Such accumulated residual N was eventually transferred into aquatic ecosystems (Rasouli et al., 2014). Conversely, eastern and southern coastal regions in Mainland China remained largely unchanged with regard to $\mathrm{N}$ application rates and even rates even decreased in Taiwan (Fig. S5a). The $\mathrm{N}$ runoff rate in these regions therefore becomes the primary driving force for $\mathrm{R}_{\mathrm{TN}}$ trends.

Likewise, we quantified the contribution of water input to the $\mathrm{R}_{\mathrm{TN}}$ trend increase in China. For rice paddy fields, our model suggests that the decreasing water input offsets $27 \%$ of the impact of fertilization on the increasing $\mathrm{R}_{\mathrm{TN}}$ trend at the national scale, and this offset effect is more clearly observed in northern China than in south (Fig. 5). Previous studies indicated that $\mathrm{R}_{\mathrm{TN}}$ tends to increase with water input (Gao et al., 2016; Hou et al., 2016), because high precipitation and irrigation events in turn resulted in 372 input mainly occurred due to the decrease in irrigation inputs, rather than a marked 
373 change in precipitation patterns, except in Taiwan, Hainan and parts of northwestern

374 China (Fig. S6a). Improving the irrigation efficiency could be an effective measure to

375 reduce the overall amount of water used for irrigation in most provinces, whereas the

376 expansion of irrigated area dominates the growth of irrigation mainly in the Northeast

377 Plain, Sichuan Basin, and Yunnan-Guizhou Plateau. Similar drivers and patterns of

378 irrigation trends are found for upland all over the country (Fig. S6b). It should be noted

379 that our per-area irrigation dataset was compiled based on total values at municipal

380 level, rather than on crop-specific amounts (Fig. S5b). Therefore, it would be valuable

381 if future research focused on surveys to address this issue by gathering data per-area

382 irrigation among different crops in each municipal area.

383

384 Our results attributing the contribution by different factors also indicate that the $\mathrm{N}$

385 runoff rate positively affected the $\mathrm{R}_{\mathrm{TN}}$ trend for uplands across most of southern China,

386 but in general had a negative effect for rice paddy fields (Fig. 5). To interpret such

387 distinct effects on $\mathrm{N}$ runoff rates, we conducted two types of scenario assessments to

388 separate the impact of changes in environmental conditions or agricultural management

389 practices: a control simulation with all conditions and practices varying from 1990 to

3902012 and an experimental simulation with one condition or practice fixed at year 1990

391 levels. The difference was considered as the response to one change in conditions or

392 practices. SOM was identified as the dominant factor for the trends of $\mathrm{N}$ runoff rate for

393 both uplands and rice paddy fields nationwide, followed by $\mathrm{N}_{\text {rate }}$ and water input (Fig. 

confirmed by observations from 63 field sites across China (Fig. S9), and could be explained by the difference in the generation process of $\mathrm{N}$ runoff. Upland $\mathrm{N}$ runoff begins when raindrops hit the ground and detach soil particles by splash. The sediments eroded from upland fields carry adsorbed $\mathrm{N}$ that is subsequently transported downstream. Therefore, high SOM may increase the risk of upland $\mathrm{N}$ runoff during 401 rainfall events (Liu et al., 2014). In contrast, $\mathrm{N}$ runoff from paddy fields increases when 402 rainfall input exceeds its storage capacity. Overflow through the paddy field levee 403 carries dissolved $\mathrm{N}$ into ponding water and rainfall-driven interstitial runoff of nitrate 404 at the soil-water interface to the surrounding water bodies (Huang et al., 2014; 405 Higashino and Stefan, 2014). High SOM improves the adsorption of soil $\mathrm{N}$ in ponding 406 water thus lowers the magnitude of N runoff from paddy fields. Additionally, high SOM 407 benefits upland $\mathrm{N}$ mineralization under aerobic environment, resulting in increases in 408 soil inorganic $\mathrm{N}$ availability and hence $\mathrm{N}$ runoff. Little inorganic $\mathrm{N}$, however, will be 409 released from SOM in paddy field under anaerobic environment, which helps reducing 410 N runoff (Wu et al., 2017).

412 In this study, we comprehensively quantified and analyzed the attribution factors for $\mathrm{N}$ 413 runoff trends in China's croplands. However, we found that some results for simulated 414 N runoff were significantly different from observations (Fig. 2). Previous experiments 
416 (e.g., methods, timing), irrigation schemes, or rainfall intensity (Liu et al., 2016;

417 Miyazato et al., 2010; Wang et al., 2015a; Xu et al., 2013). For example, field trials

418 highlighted that the application of controlled release $\mathrm{N}$ fertilizers significantly reduced

419 N runoff by 48-72\% compared to top-dressing fertilization for paddy fields. Similarly,

420 the application of optimized irrigation methods significantly reduced $\mathrm{N}$ runoff by $24 \%$

421 compared to flooding irrigation (Yang et al., 2015); N runoff from paddy fields was not

422 only passively generated by monsoon rain in China, but also a consequence of human-

423 induced drainage before transplanting (Yan et al., 2016). However, the current

424 upscaling model did not fully consider such management practices. Meanwhile, air

425 temperature and clay content were used in this study as proxies for soil temperature and

426 soil water content within the experimental period, respectively, due to the lack of long-

427 term observations across China. Although previous works have found a significant

428 linear relationship between air and soil temperatures or between clay and water contents

429 (Zheng et al., 1993; Wäldchen et al., 2012), more robust estimations of soil temperature

430 and water content become another question to be undertaken by future studies. In

431 addition, in situ measurements of N runoff are scarce in Northwest China (e.g., Xinjiang

432 province), leading to large uncertainty in $\mathrm{R}_{\mathrm{TN}}$ estimates in this regions. Previous studies

433 indicated that the dominant pathways of $\mathrm{N}$ losses would be ammonia volatilization to

434 the atmosphere and N leaching to aquifers (Gao et al., 2016; Van Damme et al., 2017),

435 rather than surface $\mathrm{N}$ runoff. More importantly, this region accounts for only $8.6 \%$ of 

makes a small overall contribution to the total $\mathrm{N}$ runoff of Chinese croplands. To confirm the contribution from Northwest China, more observations should be

440 conducted in the future to verify $\mathrm{R}_{\mathrm{TN}}$ estimates. Furthermore, data from field 441 manipulation experiments on the response of $\mathrm{R}_{\mathrm{TN}}$ to environmental conditions (e.g., 442 SOM) is lacking and would be useful to constrain our upscaling model. Therefore, 443 further efforts to make widespread measurements and to carry out field manipulation experiments for RTN are necessary to improve the reliability of such model simulations.

446 In summary, cropland $\mathrm{N}$ runoff has been increasing significantly in China for the period 447 1990-2012. At a national scale, increases in fertilizer application and decreases in 448 irrigation amounts were identified as the most likely causes for the $\mathrm{N}$ runoff trend. The 449 positive contribution of $\mathrm{N}$ runoff rate to the $\mathrm{R}_{\mathrm{TN}}$ trend is more evident in southern China 450 than in the north. We expect a continuously decreasing trend in irrigation amounts into 451 the future, and fertilizer application rates likely to plateau, since China aims to improve 452 water use as well as fertilizer $\mathrm{N}$ application efficiencies through the action plans like 453 clean water and "zero-increase fertilizer use" (Ju et al., 2016). However, current 454 projections on climate change suggest that precipitation, particularly extreme rainfall 455 events, will increase. This might further lead to $\mathrm{N}$ runoff and $\mathrm{N}$ runoff rate increase in 456 the future. In addition to the expected improvements on $\mathrm{N}$ use efficiency and water use 
457 efficiency in China's croplands, applying effective management approaches that 458 generate benefits for both $\mathrm{N}$ runoff and crop yields are urgently required to design more 459 efficient and sustainable agricultural $\mathrm{N}$ management. Improving the representations 460 associated with the effects of agricultural management practices and understanding the 461 response of $\mathrm{N}$ runoff to environmental conditions should be the priorities for the 462 agricultural modeling.

\section{Acknowledgements}

464 This study was supported by the National Key Research and Development Program of 465 China (2016YFD0800501), the National Natural Science Foundation of China 466 (41671464, 41530528, and 41561134016), National Science Foundation of Zhejiang 467 Province (LR15G030001), and 111 Project (B14001). We appreciated HWSD and 468 CMFD teams for providing soil and climate datasets, and authors who measured, 469 analyzed, and published data of $\mathrm{N}$ runoff used here.

\section{Appendix A. Supplementary data}

471 Supplementary information related to this article can be found online, including 472 Supplementary Data S1, Text S1 to S3, Tables S1 to S4, and Figures S1 to S9.

\section{References}

474 Abbaspour, K.C., Rouholahnejad, E., Vaghefi, S., Srinivasan, R., Yang, H., Klove, B., 475 2015. A continental-scale hydrology and water quality model for Europe: 

of Hydrology 524, 733-752.

Chen, X., Cui, Z., Fan, M., Vitousek, P., Zhao, M., Ma, W., Wang, Z., Zhang, W., Yan, X., Yang, J., Deng, X., Gao, Q., Zhang, Q., Guo, S., Ren, J., Li, S., Ye, Y., Wang, G., Wu, L., An, N., Wu, L., Ma, L., Zhang, W., Zhang, F., 2014. Producing more grain with lower environmental costs. Nature 514, 486-489.

Cherry, K.A., Shepherd, M., Withers, P.J., Mooney, S.J., 2008. Assessing the 484 methods. Science of the Total Environment 406, 1-23.

Cui, Z., Wang, G., Yue, S., Wu, L., Zhang, W., Zhang, F., Chen, X., 2014. Closing the 487 N-Use efficiency gap to achieve food and environmental security. Environmental Science \& Technology 48, 5780-5787.

Gao, S., Xu, P., Zhou, F., Yang, H., Zheng, C., Cao, W., Tao, S., Piao, S., Zhao, Y., Ji, X., Shang, Z., Chen, M., 2016. Quantifying nitrogen leaching response to fertilizer additions in China's cropland. Environmental Pollution 211, 241-251.

Gu, B., Ju, X., Chang, J., Ge, Y., Vitousek, P.M., 2015. Integrated reactive nitrogen budgets and future trends in China. Proceedings of the National Academy of Sciences 112, 8792-8797. estimation of non - point source pollution load in the large - scale basins of China 
Harrison, J.A., Seitzinger, S.P., Bouwman, A.F., Caraco, N.F., Beusen, A.H.W., Vorosmarty, C.J., 2005. Dissolved inorganic phosphorus export to the coastal zone: Results from a spatially explicit, global model. Global Biogeochemical Cycles 19, 367-384.

502

503

504

505

506

507

508

509

Higashino, M., Stefan, H.G., 2014. Modeling the effect of rainfall intensity on soilwater nutrient exchange in flooded rice paddies and implications for nitrate fertilizer runoff to the Oita River in Japan. Water Resources Research 50, 86118624.

Hou, X.K., Zhou, F., Leip, A., Fu, B.J., Yang, H., Chen, Y., Gao, S.S., Shang, Z.Y., Ma, L.K., 2016. Spatial patterns of nitrogen runoff from Chinese paddy fields. Agriculture, Ecosystems \& Environment 231, 246-254.

Huang, H., Ouyang, W., Guo, B., Shi, Y., Hao, F., 2014. Vertical and horizontal distribution of soil parameters in intensive agricultural zone and effect on diffuse nitrogen pollution. Soil \& Tillage Research 144, 32-40.

Ju, X.T., Gu, B.J., Wu, Y.Y., Galloway, J.N., 2016. Reducing China's fertilizer use by increasing farm size. Global Environmental Change 41, 26-32.

Liu, W.F., Yang, H., Liu, J.G., Azevedo, L.B., Wang, X.Y., Xu, Z.X., Abbaspour, K.C., Schulin, R., 2016. Global assessment of nitrogen losses and trade-offs with yields from major crop cultivations. Science of the Total Environment 572, 526-537.

Raupach, M. R., Marland, G., Ciais, P., Le Quéré, C., Canadell, J. G., Klepper, G., Field, 
C. B., 2007. Global and regional drivers of accelerating $\mathrm{CO}_{2}$ emissions. Proceedings of the National Academy of Sciences 104, 10288-10293.

Korsaeth, A., Eltun, R., 2000. Nitrogen mass balances in conventional, integrated and ecological cropping systems and the relationship between balance calculations and nitrogen runoff in an 8-year field experiment in Norway. Agriculture, Ecosystems \& Environment 79, 199-214.

Leip, A., Britz, W., Weiss, F., de Vries, W., 2011. Farm, land, and soil nitrogen budgets for agriculture in Europe calculated with CAPRI. Environmental Pollution 159, 3243-3253.

Liang, X.Q., Tian, G.M., Li, H., Chen, Y.X., Zhu, S., 2005. Study on characteristic of nitrogen and phosphorus loss from rice field by natural rainfall runoff. Journal of Soil Water Conservation 19, 59-63.

Liu, J.G., You, L.Z., Amini, M., Obersteiner, M., Herrero, M., Zehnder, A.J.B., Yang, H., 2010. A high-resolution assessment on global nitrogen flows in cropland. Proceedings of the National Academy of Sciences 107, 8035-8040.

Liu, Q., Li, Z.B., Li, P., 2014. Effect of runoff dynamic on sediment and nitrogen losses in an agricultural watershed of the southern Shaanxi region, China. Clean-Soil Air Water 42, 56-63.

Miyazato, T., Mohammed, R.A., Lazaro, R.C., 2010. Irrigation management transfer (IMT) and system of rice intensification (SRI) practice in the Philippines. Paddy and Water Environment 8, 91-97. 
Mueller, N. D., Gerber, J. S., Johnston, M., Ray, D. K., Ramankutty, N., \& Foley, J. A. 2012. Closing yield gaps through nutrient and water management. Nature, 490, 254-257.

Paerl, H.W., Hall, N.S., Peierls, B.L., Rossignol, K.L., 2014. Evolving paradigms and challenges in estuarine and coastal eutrophication dynamics in a culturally and climatically stressed world. Estuaries and Coasts 37, 243-258.

Piao, S., Yin, G., Tan, J., Cheng, L., Huang, M., Li, Y., Liu, R., Mao, J., Myneni, R.B., Peng, S., Poulter, B., Shi, X., Xiao, Z., Zeng, N., Zeng, Z., Wang, Y., 2015. Detection and attribution of vegetation greening trend in China over the last 30 years. Global Change Biology 21, 1601-1609.

Rasouli, S., Whalen, J.K., Madramootoo, C.A., 2014. Review: reducing residual soil nitrogen losses from agroecosystems for surface water protection in Quebec and Ontario, Canada: best management practices, policies and perspectives. Canadian Journal of Soil Science 94, 109-127.

Raymond, P.A., David, M.B., Saiers, J.E., 2012. The impact of fertilization and hydrology on nitrate fluxes from Mississippi watersheds. Current Opinion in Environmental Sustainability 4, 212-218.

Seitzinger, S.P., Mayorga, E., Bouwman, A.F., Kroeze, C., Beusen, A.H.W., Billen, G., Van Drecht, G., Dumont, E., Fekete, B.M., Garnier, J., Harrison, J.A., 2010. Global river nutrient export: A scenario analysis of past and future trends. Global Biogeochemical Cycles 24, 2621-2628. 
560

561

562

563

564

565

566

567

568

569

570

571

572

573

574

575

576

577

578

579

580

Schaefer, S.C., Alber, M., 2007. Temperature controls a latitudinal gradient in the proportion of watershed nitrogen exported to coastal ecosystems. Biogeochemistry 85, 333-346.

SEPA, 2002. Standard methods for the examination of water and wastewater version 4. Beijing: China Environmental Science Press.

Shen, Z.Y., Liao, Q., Hong, Q., Gong, Y.W., 2012. An overview of research on agricultural non-point source pollution modelling in China. Separation and Purification Technology 84, 104-111.

Shi, L.H., Ji, X.H., Li, H.S., Tian, F.X., Peng, H., Liu, S.B., 2010. Nitrogen and phosphorus losses from surface runoff under different application in the double cropping rice fields in Hunan (in Chinese). Chinese Journal of Agrometeorology 31, 551-557.

Sobota, D.J., Harrison, J.A., Dahlgren, R.A., 2009. Influences of climate, hydrology, and land use on input and export of nitrogen in California watersheds. Biogeochemistry 94, 43-62.

Sorooshian, S., AghaKouchak, A., Li, J.L., 2014. Influence of irrigation on land hydrological processes over California. Journal of Geophysical ResearchAtmospheres 119, 13137-13152.

Stalnacke, P., Pengerud, A., Vassiljev, A., Smedberg, E., Morth, C.M., Hagg, H.E., Humborg, C., Andersen, H.E., 2015. Nitrogen surface water retention in the Baltic Sea drainage basin. Hydrology and Earth System Sciences 19, 981-996. 
581 Streimikiene, D., Balezentis, T., 2016. Kaya identity for analysis of the main drivers of 582 GHG emissions and feasibility to implement EU "20-20-20" targets in the Baltic 583 States. Renewable \& Sustainable Energy Reviews 58, 1108-1113.

584 Ti, C.P., Yan, X.Y., 2013. Spatial and temporal variations of river nitrogen exports from 585 major basins in China. Environmental Science and Pollution Research 20, 6509$586 \quad 6520$.

587 Tilman, D., Balzer, C., Hill, J., Befort, B.L., 2011. Global food demand and the 588 Sciences, USA 108, 20260-20264.

Van Damme, M.; Whitburn, S.; Clarisse, L.; Clerbaux, C.; Hurtmans, D.; Coheur, P. F. Version 2 of the IASI NH3 neural network retrieval algorithm; near-real time and

Velthof, G.L., Oudendag, D., Witzke, H.P., Asman, W.A., Klimont, Z., Oenema, O., 2009. Integrated assessment of nitrogen losses from agriculture in EU-27 using MITERRA-EUROPE. Journal of Environmental Quality 38, 402-417.

Wäldchen, J., Schoning, I., Mund, M., Schrumpf, M., Bock, S., Herold, N., Totsche, 598 K.U., Schulze, E.D., 2012. Estimation of clay content from easily measurable water content of air-dried soil. Journal of Plant Nutrition and Soil Science 175, 367-376.

600 Wang, J., Lu, G.A., Guo, X.S., Wang, Y.Q., Ding, S.W., Wang, D.Z., 2015a. 601 Conservation tillage and optimized fertilization reduce winter runoff losses of 

Nutrient Cycling in Agroecosystems 101, 93-106.

604

606

608

Wang, S., Fu, B., Piao, S., Lü, Y., Ciais, P., Feng, X., Wang, Y., 2015b. Reduced sediment transport in the Yellow River due to anthropogenic changes. Nature Geoscience 9, 38-41.

Wang, X.L., Feng, A.P., Wang, Q., Wu, C.Q., Liu, Z., Ma, Z.S., Wei, X.F., 2014. Spatial variability of the nutrient balance and related NPSP risk analysis for agroecosystems in China in 2010. Agriculture, Ecosystems \& Environment 193, 42-52.

Wu, L., Tang, S.R., He, D.D., Wu, X., Shaaban, M., Wang, M.L., Zhao, J.S., Khan, I., Zheng, X.H., Hu, R.G., Horwath, W.R., 2017. Conversion from rice to vegetable production increases $\mathrm{N}_{2} \mathrm{O}$ emission via increased soil organic matter mineralization. Science of the Total Environment 583, 190-201.

Xu, J., Shan, L.N., Yu, D.P., Li, Z.L., He, Y.F., 2013. Effects of different fertilization modes on nitrogen use efficiency of cabbages and nitrogen loss from vegetable field (in Chinese). Journal of Zhejiang University 39, 556-564.

Yan, R., Gao, J., Huang, J., 2016. WALRUS-paddy model for simulating the hydrological processes of lowland polders with paddy fields and pumping stations. Agricultural Water Management 169, 148-161.

Yan, X., Ti, C., Vitousek, P., Chen, D., Leip, A., Cai, Z., Zhu, Z., 2014. Fertilizer nitrogen recovery efficiencies in crop production systems of China with and without consideration of the residual effect of nitrogen. Environmental Research 
624 Yang, S.H., Peng, S.Z., Xu, J.Z., He, Y.P., Wang, Y.J., 2015. Effects of water saving 625 irrigation and controlled release nitrogen fertilizer managements on nitrogen losses 626 from paddy fields. Paddy and Water Environment 13, 71-80.

627 Yu, Q.G., Ye, J., Ma, J.W., Sun, W.C., Wang, Q., Jiang, L.N., Fu, J.R., Chen, Y., 2011. 628 Effects of different nitrogen applied levels on nitrogen runoff loss in oilseed rape fields (in Chinese). Journal of Soil and Water Conservation 25, 22-25.

Zhang, X., Davidson, E.A., Mauzerall, D.L., Searchinger, T.D., Dumas, P., Shen, Y., 2015. Managing nitrogen for sustainable development. Nature 528, 51-59.

632

Zhang, Y., Zhou, Y., Shao, Q., Liu, H., Lei, Q., Zhai, X., Wang, X., 2016. Diffuse 633 nutrient losses and the impact factors determining their regional differences in four catchments from North to South China. Journal of Hydrology 543, 577-594.

Zheng, D., Hunt Jr., E.R. and Running, S.W. 1993. A daily soil temperature model based on air temperature and precipitation for continental applications. Climate Research, 2, 183-191.. 